\title{
Concomitant Boost Versus Sequential Boost in Breast Conservative Therapy for Early Stage Breast Cancer
}

\author{
Salah El-Mesidy ${ }^{1}$, Asmaa Ali Hassan, Mohamed Abdelrahman, Shaimaa Lasheen, \\ Waleed Hammam and Maha Kamal El-Din²
}

\author{
${ }^{1}$ Department of Clinical Oncology, Faculty of Medicine, Cairo University. ${ }^{2}$ Department of clinical \\ oncology, physics unit, Faculty of Medicine, Cairo University.
}

Purpose/objective: To compare concomitant boost irradiation (CBI) to sequential boost irradiation (SBI) to the tumor bed by 3DCRT after breast-conserving surgery (BCS) regarding target coverage, dose homogeneity, dose to organs at risk, acute toxicity, late toxicity, local control, DFS and cosmesis.

Materials/Methods: Sixty patients were randomized after BCS to receive concomitant boost irradiation for 5 weeks (for each fraction, the breast and boost planning target volumes "PTVs" received 2 Gy and 2.4 Gy, to a total dose of 50 Gy and 60 Gy respectively) or a biologically equivalent sequential boost (the breast received 2 Gy x 25 fractions followed by 2 Gy x 8 fractions boost to the tumor bed). Three-dimensional conformal beams with wedges were used. Acute toxicity was evaluated using RTOG criteria and cosmesis was evaluated using Gray score.

Results: Target coverage was adequate with both techniques (V45 for breast CTV $=98.5 \%$ vs $98.7 \%$ for CBI and SBI respectively, $P=0.6$; and D95 for boost PTV -after calculation of biologically equivalent dose "BED"= 62.9 Gy vs $63.3 \mathrm{~Gy}$, respectively). There was no statistically significant difference between the two groups regarding the doses to OAR (i.e. mean heart dose, heart V40, lung V20, mean dose to contralateral breast and mean dose to the thyroid gland). The 2 groups were comparable regarding cardiac, pulmonary, neurologic and skin toxicity with 20 (33.4\%) of our patients developing GII or worse skin toxicity, but with no impact on cosmetic outcome (median=7 in each arm, $P=0.8$ ). After a median follow-up of 25 months, disease free survival was $83.3 \%$ in the sequential arm versus $93.3 \%$ in the concomitant arm $(P$-value $=0.170)$. Only one patient in the study developed local recurrence; that patient was in the sequential boost arm, with loco-regional recurrence free survival (LRRFS) of $95.1 \%$ for our whole patient cohort.

Conclusion: Concomitant boost irradiation by 3DCRT is non-inferior to sequential boost irradiation after BCS regarding acute toxicity, cosmetic outcome, local control and DFS. It can be used to reduce the number of treatment fractions without increasing toxicity or hindering patient outcome.

Key words: concomitant boost, breast-conserving therapy Corresponding Author: Salah El-Mesidy

E-mail: salahelmesidy@hotmail.com

\section{INTRODUCTION}

Breast cancer is the most common cancer in females, with nearly 1 million new cases worldwide annually ${ }^{1}$. For many years, mastectomy was the standard treatment to achieve local control in breast cancer. Breastconserving therapy (BCT) was developed and resulted in an equivalent survival in several phase III trials ${ }^{2}$. A meta-analysis of the Early Breast Cancer Trialists Collaborative Group (EBCTCG) revealed that breast irradiation was associated with a $17.9 \%$ absolute reduction in the 10-year rate of local recurrence $(26.2 \%$ without radiation vs $8.3 \%$ with radiation) and a $3.6 \%$ absolute reduction in the 15 year rate of breast cancer mortality $(25.3 \% \text { vs } 21.7 \% \text {, respectively; } P=.0003)^{3}$.

A dose-response relationship has also been demonstrated in the "EORTC 22881-10882 boost versus no boost trial" where significantly fewer local failures were seen among young patients ( $<50$ years) who received an additional boost of 16 Gray in 8 fractions to the tumor bed ${ }^{4}$. Lately this significant effect has also been demonstrated in patients $>50$ years with longer follow-up, the overall hazard ratio being 0.59 (95\% CI, 0.46-0.76) in favour of boost, however, the absolute risk reduction is most pronounced among women $<50$ years ${ }^{5}$.

Traditionally, external radiotherapy consists of two planned phases: first, 50 Gy or an equivalent biological dose is delivered to the whole breast in 25 fractions over 5 weeks, followed by 10-16 Gy delivered in 5-8 fractions over 1-2 weeks to the tumor bed ${ }^{6}$. Despite its proven effectiveness and safety, conventionally 
fractionated WBI has certain shortcomings, including the inconvenience to patients undergoing daily treatment for 6-7 weeks and the cost of treatment (both direct health care expenditures and costs to the patient and society due to time away from home and work) ${ }^{7}$.

Recent advances are focused on the reduction of overall treatment time by delivering a dose biologically equivalent to the standard schedule ${ }^{8}$. Planning of the boost dose on the surgical bed during WBI appears particularly appealing in this context. The radiotherapy course may be shortened by 1 or 2 weeks, and a greater dose per fraction can be delivered to the area at high risk of residual microscopic cancer cells ${ }^{9}$. A simultaneous boost has been introduced in clinics by using 3-D conformal radiotherapy or intensity-modulated radiotherapy. Preliminary results from experiences where a boost dose was delivered either daily after whole-breast irradiation (WBI) or weekly as the sixth fraction appear interesting, with a good feasibility in terms of acute toxicity ${ }^{9-11}$.

The aim of this study is to compare the delivery of a concomitant boost versus a conventional sequential boost to the tumor bed in the postoperative management of breast cancer following breast conservative surgery regarding local control, acute toxicity, late toxicity and cosmetic outcome.

\section{PATIENTS AND METHODS}

This is a non-inferiority prospective phase II openlabel randomized study carried out at Kasr El-Aini Center of Clinical Oncology \& Nuclear Medicine (NEMROCK) during the period between July 2010 and December 2012. Sixty patients were recruited and randomized into 2 groups; 30 patients were treated using a concomitant boost and 30 were treated using a conventional sequential boost.

Inclusion criteria included female patients, aged 18-70 years, WHO performance status 0-2, after BCS with negative surgical margins and pathologically proven breast carcinoma pT1-2 and pN0-3 without distant metastases. Patients with a positive pregnancy test, contra-indication to breast irradiation or history of another malignancy, were excluded.

\section{Target delineation:}

CT acquisition was carried out for each patient in the treatment position. LASER beam was used to define the reference point. Multiple fine cuts of $\leq 5 \mathrm{~mm}$ thickness were obtained from the chin to the upper abdomen. All cuts were then transferred to the treatment planning system "Eclipse version 7.6". Delineation of the target volume i.e. whole breast-CTV, supra-clavicular lymph nodes and lumpectomy cavity as well as well as the organs at risk including the heart, lungs, spinal cord, contra-lateral breast and thyroid was done. The definition of the lumpectomy cavity was guided by the presence of surgical clips-if present, as well as by hematoma, seroma or other surgery-induced changes considered to be part of the lumpectomy cavity, or by ultrasound. The boost clinical target volume (B-CTV) was generated by adding a 3-D margin of $10 \mathrm{~mm}$ around the lumpectomy cavity. The boost planning target volume (B-PTV) was accordingly generated by adding a further margin of 5 $\mathrm{mm}$.

\section{D planning:}

The breast was treated isocentrically using 2 tangential beams with selective multi-leaf blocking to protect risk organs (WBI). Two plans for treatment of the tumor bed were generated; one using photon and another using electron to cover the tumor bed PTV with maximum sparing of risk organs.

Plan summation was done twice for every patient; once for WBI plan and B-PTV photon plan, then again for WBI plan and B-PTV electron plan. Each summated plan was then reviewed, and after comparing both plan sums one was chosen for treatment (photon or electron) before randomization. Each plan was reviewed regarding target coverage, homogeneity and doses to organs at risk.

\section{Randomization:}

Patients were blindly randomized using the closed envelope method into 2 arms:

1. Arm (A): received Whole breast irradiation "WBI" at a dose of 50 Gy in 25 fractions delivered in 5 weeks, followed by a boost to the lumpectomy cavity of 16 Gy in 8 fractions (total dose $66 \mathrm{~Gy} / 33$ fractions in 6.6 weeks).

2. Arm (B): received "WBI" at a dose of 50 Gy in 25 fractions in 5 weeks with a concomitant boost to the tumor bed PTV in daily fractions of $40 \mathrm{cGy}$ immediately after WBI. Accordingly, the whole breast received the conventional dose of $50 \mathrm{~Gy} / 25$ fractions while the tumor bed received a dose of 60 Gy in 25 fractions at 2.4 Gy fractions in 5 weeks. The biologically equivelant dose (BED) for both regimens was calculated using the linear quadratic (LQ) model. For this purpose, an $\alpha / \beta$ ratio of 10 for early reacting tissues and an $\alpha / \beta$ ratio of 3 for lateresponding normal tissues were used ${ }^{12}$, while for the tumor, an $\alpha / \beta$ ratio of 4 was used ${ }^{13}$.

The study end points included two-years local recurrence (assessed by clinical examination and mammo-sonography), acute Toxicity (assessed according to the RTOG toxicity criteria), late toxicity (late lung 
toxicity was assessed by clinical examination, chest x-ray and pulmonary function test repeated at the end of the study while late cardiac toxicity was assessed by clinical examination and echocardiography repeated at the end of the study) and cosmesis and late effects (assessed according to the criteria reported by ${ }^{14}$.

\section{Statistical Analysis:}

Data management and analysis were performed using Statistical Package for Social Sciences (SPSS) vs. ${ }^{17}$. Numerical data were summarized using means and standard deviations or medians and ranges. Categorical data were summarized as percentages. Comparisons between the two groups with respect to normally distributed numeric variables were done using the $t$-tests. Non-normally distributed numeric variables were compared by Mann-Whitney test, a nonparametric test equivalent to the Student's $t$-test. The chi-square test or Fisher's exact test were used to compare between the groups with respect to categorical data. Disease free survival time was estimated using the methods of Kaplan and Meier. Differences between survival curves were assessed for statistical significance with the log-rank test.

\section{RESULTS}

This study included sixty patients with a median followup period of 25 months (ranging from 14.3 to 32.9 months).

Both arms were balanced regarding all clinical features (table 1) and patients' body measures. The two groups were also balanced regarding the pathological features i.e. pathological type (IDC versus other pathological types), grade, percentage of intra-ductal component, tumor size, number of positive nodes, ER, PR and Her-2-neu status (Table 2).

IDC: Invasive duct carcinoma, ILC: Invasive lobular carcinoma, SD: Standard deviation, ER: Estrogen receptor, PR: Progesterone receptor, ND: Not defined.

\section{Dosimetric results:}

The coverage and homogeneity of the CTV (the whole breast) was assessed using the V45 Gy, the D95\%, Dmax and Dmin. These parameters were compared between both groups revealing no statistically significant differences. For the (B-PTV), the V45 Gy, D95\%, Dmax and Dmin were used. To account for the altered fractionation received in the concomitant arm (tumor bed received a hypofractionated dose of $2.4 \mathrm{~Gy}$ daily fractions to a total dose of $60 \mathrm{~Gy}$ ), an $\alpha / \beta$ ratio of 413 was used to calculate the BED for the dosimetric parameters for the dose received by the boost cavity in the concomitant arm, and it was found that all dosimetric parameters were comparable between the two groups with non-statistically significant $\mathrm{P}$-values (Table 3 ).
The doses received by organs at risk were evaluated by several dosimetric parameters. The dose to the heart was evaluated by the V40 Gy, D50\% and MHD. The ipsilateral lung evaluation was based mainly on the V20 Gy as well as the mean lung dose. The dose received by the contralateral breast was compared between the two groups using the parameters of V5 Gy and Dmean. The thyroid gland was assessed by the mean dose received. There were no statistically significant differences between the two groups regarding all these dosimetric parameters used to evaluate the doses to the OAR (Table 4).

\section{Clinical results:}

Out of the 30 patients receiving sequential boost, 16 received electron boost and 14 received photon boost; while in the concomitant arm, 8 received electron and 22 photon boost. This difference was found to be of statistical significance with a $P$-value of 0.035 . The mean duration of the whole course of radiation (in days) was found to be $48.5+/-2.8$ days for the sequential arm, and only $37.1+/-3.2$ days for the concomitant $\operatorname{arm}(P$-value $<0.001)$. There was a lag (delay) in the completion of the course of irradiation in the range of 0-11 days (median=4 days) for the sequential arm, and in the range of 0-9 days (median $=3.5$ days) for the concomitant arm, this difference was not statistically significant.

Out of the 60 patients in this study, only one patient developed local recurrence (in the sequential arm). The LRRFS (Loco-regional recurrence-free survival) for the whole patient population was found to be $95.1 \%$ at 24 months. The 24-months DFS was compared between both groups and showed no statistically significant difference $(P$-value $=0.170)$; where 3 patients in the sequential arm developed distant metastases and in the concomitant arm 2 patients did (figure 1).

\section{Toxicity \& cosmetic outcome:}

In arm (A) 12 patients (40\%) developed grade I cardiac toxicity, while in arm (B) 9 (30\%) developed grade I toxicity. This difference did not reach statistical significance $(P$-value $=0.417)$. None of our sixty patients developed grade II-IV toxicity. The EF (ejection fraction) was found to decrease with time i.e. percentage decrease of post-treatment EF versus pretreatment value, and this decrease was of high statistical significance $(P$-value $<0.001)$. This difference was found for the whole group of patients, but was not found between the two arms $(P$-value $=0.275)$.

The two arms were compared regarding pulmonary toxicity; where in arm (A) 14 patients (46.7\%) experienced grade I-II toxicity, while in arm (B) 11 $(36.7 \%)$ experienced grade I-II toxicity, this difference was not statistically significant $(P$-value $=0.432)$. The 
pre-treatment and post-treatment FEV1/FVC were comparable between the two groups, and did not show change over time. There was no statistically significant difference between both arms regarding grade 0 \& grade I-II brachial plexopathy by the end of the study as assessed by the RTOG toxicity scale $(P$-value $=0.273)$.

Out of the 30 patients who received sequential boost irradiation, 22 experienced grade I skin toxicity and 8 experienced grade II or III toxicity, while 18 patients in the concomitant arm had grade I toxicity and 12 had grade II or III toxicity. This difference was not statistically significant $(P$-value $=0.273)$. Of our sixty patients, four patients (two in the concomitant arm and two in the sequential arm) developed grade III toxicity.

All the patients in the present study were evaluated and designated a cosmetic score based on the criteria described by Gray et al. ${ }^{14}$. The cosmetic score (Gray score) designated for our patients ranged from score "4" i.e. poor, to score " 8 " i.e. excellent cosmesis. The cosmetic score of patients in both groups were compared and no statistically significant difference was found between the two groups $(P$-value $=0.867)$.

Table 1: Clinical features of patients

\begin{tabular}{|c|c|c|c|}
\hline & $\operatorname{Arm}(\mathbf{A})$ & $\operatorname{Arm}(B)$ & $P$-value \\
\hline $\begin{array}{l}\text { Age (years): } \\
\text {-median } \\
\text {-mean+/-SD } \\
\text {-range }\end{array}$ & $\begin{array}{c}49 \\
48.6+/-8.1 \\
33-63 \\
\end{array}$ & $\begin{array}{c}51 \\
49.9+/-10.1 \\
30-69 \\
\end{array}$ & 0.584 \\
\hline $\begin{array}{l}\text { Menopausal status: } \\
\text {-pre-menopausal } \\
\text {-post-menopausal }\end{array}$ & $\begin{array}{l}20(66.7 \%) \\
10(33.3 \%)\end{array}$ & $\begin{array}{l}15(50 \%) \\
15(50 \%)\end{array}$ & 0.190 \\
\hline $\begin{array}{l}\text { Side: } \\
\text {-right } \\
\text {-left }\end{array}$ & $\begin{array}{l}10(33.3 \%) \\
20(66.7 \%)\end{array}$ & $\begin{array}{l}14(46.7 \%) \\
16(53.3 \%)\end{array}$ & 0.292 \\
\hline $\begin{array}{l}\text { Site: } \\
\text {-UOQ \& central } \\
\text {-Other }\end{array}$ & $\begin{array}{l}18(60 \%) \\
12(40 \%)\end{array}$ & $\begin{array}{c}21(70 \%) \\
9(30 \%)\end{array}$ & 0.417 \\
\hline $\begin{array}{l}\text { Medical history: } \\
\text {-DM } \\
\text {-HTN } \\
\text {-Both } \\
\text {-none }\end{array}$ & $\begin{array}{c}2(6.7 \%) \\
4(13.3 \%) \\
2(6.7 \%) \\
22(73.3 \%)\end{array}$ & $\begin{array}{c}2(6.7 \%) \\
4(13.3 \%) \\
2(6.7 \%) \\
22(73.3 \%)\end{array}$ & 1.0 \\
\hline $\begin{array}{l}\text { Chemotherapy: } \\
\text {-anthracycline-based } \\
\text {-taxane-based } \\
\text {-no chemotherapy }\end{array}$ & $\begin{array}{c}17(56.7 \%) \\
7(23.3 \%) \\
6(20 \%)\end{array}$ & $\begin{array}{c}14(46.7 \%) \\
10(33.3 \%) \\
6(20 \%)\end{array}$ & 0.365 \\
\hline $\begin{array}{l}\text { Baseline Cardiac } \\
\text { function }(\mathrm{EF} \%) \text { :- } \\
\text { mean+/-SD } \\
\text { - range }\end{array}$ & $\begin{array}{c}65+/-5.0 \\
53-74\end{array}$ & $\begin{array}{c}63.7+/-4.7 \\
56-77\end{array}$ & 0.352 \\
\hline $\begin{array}{l}\text { Baseline } \\
\text { Pulmonary function } \\
\text { (FEV1/FVC)\%: } \\
\text {-mean+/-SD } \\
\quad \text { - range }\end{array}$ & $\begin{array}{c}79.3+/-3.5 \\
72-84\end{array}$ & $\begin{array}{c}79+/-4.0 \\
70-86\end{array}$ & 1.0 \\
\hline
\end{tabular}

UOQ: Upper outer quadrant, DM: Diabetes Mellitus, HTN: Hypertension, EF: Ejection fraction, FEV1: Forced expiratory volume in 1st second, FVC: Forced vital capacity
Table 2: Pathological features

\begin{tabular}{|c|c|c|c|}
\hline & $\operatorname{Arm}(A)$ & Arm (B) & $P$-value \\
\hline $\begin{array}{l}\text { Pathological type: } \\
\text {-IDC } \\
\text {-Other (ILC/ Medullary ca) }\end{array}$ & $\begin{array}{c}29(96.7 \%) \\
1(3.3 \%) \\
\end{array}$ & $\begin{array}{c}26(86.7 \%) \\
4(13.3 \%) \\
\end{array}$ & 0.353 \\
\hline $\begin{array}{l}\text { Pathological grade: } \\
\text {-Grade II } \\
\text {-Grade III } \\
\text {-ND }\end{array}$ & $\begin{array}{c}25(83.3 \%) \\
3(10 \%) \\
2(6.7 \%)\end{array}$ & $\begin{array}{c}26(86.6 \%) \\
2(6.7 \%) \\
2(6.7 \%)\end{array}$ & 1.0 \\
\hline $\begin{array}{l}\text { Intra-ductal component: } \\
-<25 \% \\
->25 \% \\
-0 \% \\
\end{array}$ & $\begin{array}{c}11(36.6 \%) \\
3(10 \%) \\
16(53.3 \%) \\
\end{array}$ & $\begin{array}{c}6(20 \%) \\
2(6.7 \%) \\
22(73.3 \%) \\
\end{array}$ & 0.257 \\
\hline $\begin{array}{l}\text { T-stage: } \\
-\mathrm{T}_{1} \\
-\mathrm{T}_{2}\end{array}$ & $\begin{array}{l}10(33.3 \%) \\
20(66.7 \%)\end{array}$ & $\begin{array}{c}8(26.7 \%) \\
22(73.3 \%)\end{array}$ & 0.573 \\
\hline $\begin{array}{l}\text { Tumor size }(\mathrm{cm}) \text { : } \\
\text {-mean }+/-\mathrm{SD} \\
\text { - range }\end{array}$ & $\begin{array}{c}2.7+/-1.2 \\
0.5-5.0\end{array}$ & $\begin{array}{c}2.8+/-1.2 \\
1.2-0.5\end{array}$ & 0.678 \\
\hline $\begin{array}{l}\mathrm{N} \text {-stage: } \\
-\mathrm{N}_{0} \\
-\mathrm{N}_{1}, \mathrm{~N}_{2}, \mathrm{~N}_{3}\end{array}$ & $\begin{array}{l}18(60 \%) \\
12(40 \%) \\
\end{array}$ & $\begin{array}{c}23(76.7 \%) \\
7(23.3 \%) \\
\end{array}$ & 0.165 \\
\hline $\begin{array}{l}\text { Number of positive nodes: } \\
\text { - range } \\
-0 \\
-1-3 \\
-\geq 4\end{array}$ & $\begin{array}{c}0-11 \\
18(60 \%) \\
5(16.7 \%) \\
7(23.3 \%) \\
\end{array}$ & $\begin{array}{c}0-12 \\
23(76.7 \%) \\
5(16.7 \%) \\
2(6.7 \%) \\
\end{array}$ & $\begin{array}{r}0.141 \\
- \\
\end{array}$ \\
\hline $\begin{array}{l}\text { ER-status: } \\
\text {-positive } \\
\text {-negative }\end{array}$ & $\begin{array}{c}23(76.7 \%) \\
7(23.3 \%)\end{array}$ & $\begin{array}{l}18(60 \%) \\
12(40 \%)\end{array}$ & 0.165 \\
\hline $\begin{array}{l}\text { PR-status: } \\
\text {-positive } \\
\text {-negative }\end{array}$ & $\begin{array}{l}20(66.7 \%) \\
10(33.3 \%)\end{array}$ & $\begin{array}{l}17(56.7 \%) \\
13(43.3 \%)\end{array}$ & 0.426 \\
\hline $\begin{array}{l}\text { Her-2-neu status: } \\
\text {-negative (score } 0,1 \text { ) } \\
\text {-Indeterminate (score2) } \\
\text {-positive (score } 3 \text { ) }\end{array}$ & $\begin{array}{c}19(63.3 \%) \\
5(16.7 \%) \\
6(20 \%)\end{array}$ & $\begin{array}{l}18(62.1 \%) \\
6(20.7 \%) \\
5(17.2 \%)\end{array}$ & 0.908 \\
\hline $\begin{array}{l}\text { IDC: Invasive duct carcinome } \\
\text { deviation, ER: Estrogen recep }\end{array}$ & $\begin{array}{l}\text { C: Invasive lol } \\
\text {, PR: Progester }\end{array}$ & $\begin{array}{l}\text { ar carcinoma, } \mathrm{S} \\
\text { e receptor, ND: }\end{array}$ & $\begin{array}{l}\text { Standard } \\
\text { t defined }\end{array}$ \\
\hline
\end{tabular}

Table 3:Dosimetric data on coverage of the CTV \& B-PTV

\begin{tabular}{llll}
\hline Parameter & Arm (A) & Arm (B) & $P$-value \\
\hline CTV (WBI) & & & \\
\hline $\begin{array}{l}\text { V45Gy in \% } \\
\text { (mean +/-SD) }\end{array}$ & $98.5+/-2.2$ & $98.7+/-0.9$ & 0.616 \\
\hline $\begin{array}{l}\text { D95\% in Gy } \\
\text { (mean +/-SD) }\end{array}$ & $48.3+/-1.7$ & $48.3+/-0.7$ & 0.801 \\
\hline $\begin{array}{l}\text { Dmax. in Gy } \\
\text { (mean +/-SD) }\end{array}$ & $53.2+/-1.1$ & $52.9+/-0.8$ & 0.265 \\
\hline $\begin{array}{l}\text { Dmin. in Gy } \\
\text { (mean +/-SD) }\end{array}$ & $45.2+/-1.5$ & $45.1+/-1.7$ & 0.788 \\
\hline Boost-PTV & $100+/-0.2$ & $99.9+/-0.2$ & 0.769 \\
\hline $\begin{array}{l}\text { V45Gy in \% } \\
\text { (mean +/-SD) }\end{array}$ & $62.9+/-2.0$ & $63.3+/-1.3$ & 0.438 \\
\hline $\begin{array}{l}\text { D95\% in Gy } \\
\text { (mean +/-SD) }\end{array}$ & $67.0+/-1.3$ & $67.1+/-0.8$ & 0.863 \\
\hline $\begin{array}{l}\text { Dmax. in Gy } \\
\text { (mean +/-SD) }\end{array}$ & $60.3+/-3.8$ & $59.7+/-2.7$ & 0.500 \\
\hline $\begin{array}{l}\text { Dmin. in Gy } \\
\text { (mean +/-SD) }\end{array}$ & & & \\
\hline CTV: Cin 6 & & & \\
\hline
\end{tabular}

CTV: Clinical target volume, B-PTV: Boost planning target volume, WBI: Whole breast irradiation, V45: Volume that received 45 Gy, D95\%: dose received by $95 \%$ of the volume, Dmax: maximum dose, Dmin: minimum dose. 
Kasr-El-Aini Journal Of Clinical Oncology And Nuclear Medicine

Vol. 9 | No. 3-4 $2013 \quad$ Concomitant Boost Versus Sequential Boost

Table 4: Dosimetric data for OAR

\begin{tabular}{llll}
\hline Parameter & Arm (A) & Arm (B) & $P$-value \\
\hline Heart & & & \\
\hline $\begin{array}{l}\text { V40Gy in \% } \\
\text { (mean +/-SD) }\end{array}$ & $1.4+/-2.2$ & $1.0+/-1.6$ & 0.431 \\
\hline $\begin{array}{l}\text { D50\% in Gy } \\
\text { (mean +/-SD) }\end{array}$ & $1.34+/-0.61$ & $1.32+/-0.93$ & 0.241 \\
\hline $\begin{array}{l}\text { MHD in Gy } \\
\text { (mean +/-SD) }\end{array}$ & $3.01+/-1.91$ & $2.63+/-1.89$ & 0.391 \\
\hline $\begin{array}{l}\text { Lung } \\
\text { V20Gy in\% } \\
\text { (mean +/-SD) }\end{array}$ & $16.4+/-4.5$ & $16.0+/-4.1$ & 0.732 \\
\hline $\begin{array}{l}\text { Mean lung dose } \\
\text { in Gy (mean } \\
+/-S D)\end{array}$ & $2.4+/-1.5$ & $2.3+/-1.5$ & 0.793 \\
\hline
\end{tabular}

Contra-lateral breast

\begin{tabular}{lccc}
\hline $\begin{array}{l}\text { V5Gy in \% } \\
\text { (range) }\end{array}$ & $0-2.2$ & $0-3.5$ & 0.291 \\
\hline $\begin{array}{l}\text { Mean dose } \\
\text { in Gy }\end{array}$ & $0.79+/-0.42$ & $0.64+/-0.40$ & 0.094 \\
\hline Thyroid gland & & \\
\hline $\begin{array}{l}\text { Mean dose in } \\
\text { Gy (range) }\end{array}$ & $0.3-35.2$ & $0.4-34.5$ & 0.440 \\
\hline $\begin{array}{l}\text { V40Gy: Volume received 40 Gy, D50\%: Dose received by 50\% of the volume, } \\
\text { MHD: Mean heart dose, V20 Gy: Volume received 20 Gy, MLD: Mean lung } \\
\text { dose, V5 Gy: Volume received 5 Gy, }\end{array}$ & \\
\hline
\end{tabular}

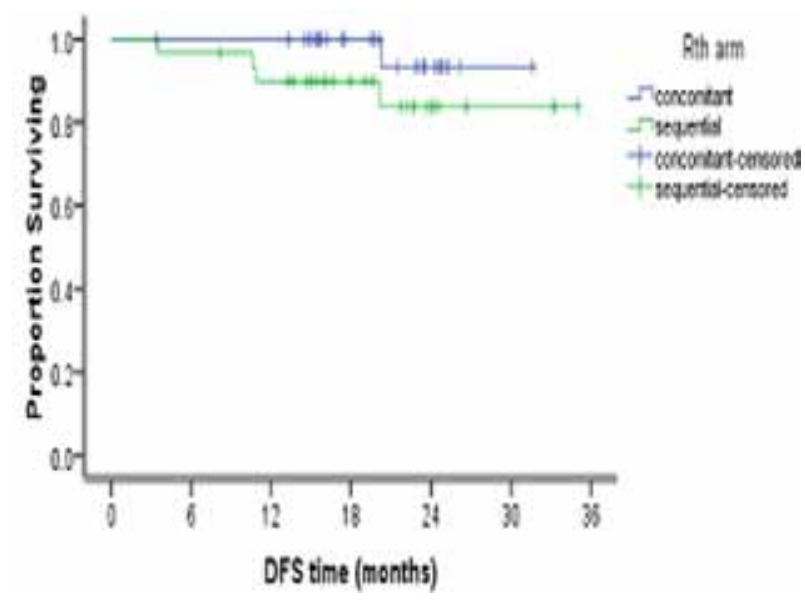

Figure 1: 24-months DFS in both groups.

\section{DISCUSSION}

The St Gallen International Expert Consensus on the Primary Therapy of Early Breast Cancer 2013 stated that clinical trial evidence supports the validity of hypofractionated radiotherapy and that such short course whole breast radiation therapy has obvious advantages in terms of patient convenience and $\operatorname{cost}^{15}$.
Another method to shorten the overall treatment time is concomitant boost irradiation. To date, at least 15 reports have described clinical or radiation planning experiences with CBRT, in the context of local control, toxicity, and dosimetric coverage $\mathrm{e}^{9-11,16-28}$. Overall, CBRT has been observed to be feasible and safe, although there have been widely varying treatment techniques and doses with total plus boost regimens ranging from 44 Gy in 16 fractions over 3.2 weeks, to 73.78 Gy in 31 fractions over 5.6 weeks. With the exception of two studies, all others delivered the concomitant boost daily with $\mathrm{WBI}^{9,21}$.

Patients in both groups were balanced regarding their baseline clinical features. The median age in arm "A" was 49 and in arm "B" 51 years, also about $58 \%$ of our patients were premenopausal. This is in contrast to international figures e.g. the SEER data document the median age at diagnosis for cancer of the breast to be 61 years of age ${ }^{29}$. One explanation for this difference comes from Egyptian data of breast cancer epidemiology, where the data of the Gharbiah cancer registry identified 3673 breast cancer patients having a median age of 50.130, while NCI of Egypt point to a median age of 46 years at presentation ${ }^{31}$.

The two arms were also balanced regarding their pathological features. In this study, more than $65 \%$ of the patients had hormone receptor positive breast cancer, which is lower than data from the SEER reporting hormone-receptor positive breast cancer to represent $75 \%$ of invasive breast cancers ${ }^{32}$. As for Her-2-neu expression, about $18 \%$ of the patients had over-expression of Her-2-neu by IHC, these figures are consistent with international figures, e.g. in the U.S. HER2 gene amplification was reported to be present in $15 \%-30 \%$ of invasive breast cancers ${ }^{32}$. But as patient recruitment for this study started in 2010, we don't have data on Ki-67 expression in these patients as at the time the test was not routinely done at our department.

In this study, we compared the dosimetric data for target coverage in both groups. The study revealed no significant differences between both techniques in coverage or dose homogeneity (V45Gy, D95\%, Dmax. and Dmin.) for the CTV and the SCLN-PTV. As for the Boost-PTV, we calculated the BED for the dose received by the tumor bed-using an $\alpha / \beta$ ratio of 413 -to account for the hypofractionated dose received in the concomitant boost arm (2.4 Gy daily versus 2 Gy in the conventional arm). The dosimetric data for the BoostPTV i.e. V45, D95\%, Dmax and Dmin were found to be of no statistically significant difference between the two groups. This is similar to the data reported by Van der Laan et al. comparing conformal simultaneously integrated boost to sequential boost ${ }^{11}$. Other reports of 


Vol. 9 | No. 3-4 $2013 \quad$ Salah El-Mesidy et al.

simultaneous integrated boost using IMRT also report excellent data on boost coverage ${ }^{33-34}$.

The dosimetric data on the doses received by the risk structures i.e. the lung, heart, skin and thyroid gland, were reported. For the heart, V40 was $1.4 \%$ in the sequential arm versus $1.0 \%$ in the concomitant arm $(P$-value $=0.43)$; and the mean dose was 3 Gy vs. $2.63 \mathrm{~Gy}(P$-value $=0.39)$. Van der Laan et al. reported a MHD of 5.3 Gy for the sequential arm vs. 4.8 Gy for the concomitant $\mathrm{arm}^{11}$. In multiple reports of SIB using IMRT, the mean heart dose ranged from 2.2- 4.1 $\mathrm{Gy}^{19,33,34}$.

For the lung, the two arms were compared using the parameters of V20, mean lung dose and mean lung distance. The sequential arm was comparable to the concomitant arm in that regard with a V20 of $16.4 \%$ vs. $16.0 \%$ respectively, a mean lung dose of 2.4 Gy vs. 2.3 Gy and a mean lung distance of 2.0 vs. $1.9 \mathrm{~cm}$ (P-value insignificant in all these parameters). This is similar to the findings reported by El-Mesidy et al. with a V20 of 18.2-24.4 Gy $\mathrm{Gy}^{35,36}$

The contra-lateral breast mean dose and V5 were compared between the two groups. The mean dose for the contra-lateral breast was $0.79 \mathrm{~Gy}$ in the sequential arm versus $0.64 \mathrm{~Gy}$ in the concomitant arm $(P$-value $=0.094)$. This is comparable to reports of concomitant boost irradiation reporting a mean dose to the contra-lateral breast in the range of $0.5-2.0$ Gy ${ }^{11,19,34,37}$.

The groups were compared regarding the received radiotherapy course duration and lags. No statistically significant difference was found in the median radiotherapy lag in days (4 days for the sequential arm and 3.5 for the concomitant arm, $P$-value $=0.976$ ). Most of these disruptions of our patients' radiotherapy courses are attributed to machine breaks and long holidays which may be up to one week, and to a lesser extent due to toxicity. In the concomitant arm, 2 patients $(6.7 \%)$ had interruptions of their radiotherapy courses due to the development of moist skin desquamation, and in one patient the last radiotherapy session was omitted. As for the sequential arm, 2 patients (6.7\%) developed moist desquamation warranting interruption of their radiotherapy course.

Patients were kept under follow-up, where in the sequential arm 3 patients $(10 \%)$ developed distant metastasis, while in the concomitant arm 2 patients (6.7\%) developed distant metastasis. All these patients were at high risk for relapse either due to $\mathrm{N} 2+$ disease, Her-2-neu overexpression or both. The 24 months disease free survival for patients in the sequential arm was $83.3 \%$ versus $93.3 \%$ for patients in the concomitant
$\operatorname{arm}(P$-value $=0.170)$. As for local recurrence, only one patient in the study developed local recurrence; that patient was in the sequential boost arm. Therefore, the 24 months LRRFS for our whole patient cohort is $95.1 \%$.

Adverse events were reported using the RTOG toxicity criteria, and there was no significant difference between the groups in cardiac, pulmonary, neurological and skin toxicity. There was also no significant difference in the patients' cosmetic outcome as reported in term of their Grey score.

\section{CONCLUSION}

Concomitant boost irradiation by 3DCRT is noninferior to sequential boost irradiation after BCS regarding acute toxicity, cosmetic outcome, local control and DFS. It can be used to reduce the number of treatment fractions without increasing toxicity or hindering patient outcome. Prolonged follow up and further larger studies are highly recommended to better evaluate late effects on normal tissues.

\section{REFERENCES}

1. Brinton L.A., Althuis M.D., Dozier J.M., et al. (2005). Global trends in breast cancer incidence and mortality 1973-1997: International Journal of Epidemiology; 34(2):405-412.

2. Van de Steene J., Vinh-Hung V., Cutuli B., et al. (2004). Adjuvnat RT for BC: effects of longer follow-up. Radiother. Oncol. ;72(1):35-43.

3. Early Breast Cancer Trialists' Collaborative Group (EBCTCG), Darby S, McGale P, Correa C, et al. (2011). Effect of radiotherapy after breast-conserving surgery on 10-year recurrence and 15-year breast cancer death: metaanalysis of individual patient data for 10,801 women in 17 randomised trials. Lancet, 378(9804), 1707-16.

4. Bartelink, H., Horiot, J., \& Poortmans P, et al. (2001). Recurrence rates after treatment of breast cancer with standard radiotherapy with or without additional radiation. New England Journal of Medicine, 345(19), 1378-1387.

5. Bartelink H., Horiot J.C., Poortmans P.M., et al. (2007). Impact of a higher radiation dose on local control and survival in breast-conserving therapy of early breast cancer: 10-year results of the randomized boost versus no boost EORTC 22881-10882 trial. J. Clin. Oncol.; 25(22):3259-3265.

6. Shafiq J., Delaney G., Barton M.B. (2007). An evidencebased estimation of local control and survival benefit of radiotherapy for breast cancer. Radioth Oncol, 84: 11-17.

7. Whelan, TJ, Levine, M., Julian, J., et al. (2000). The effects of radiation therapy on quality of life of women with breast carcinoma: results of a randomized trial. Ontario Clinical Oncology Group. Cancer, 88(10), 2260-6. 
8. Sanders M.E., Scroggins T., Ampil F.L., et al. (2007). Accelerated partial breast irradiation in early-stage breast cancer. J Clin Oncol, 25: 996-1002.

9. Corvò, R., Giudici, S., Maggio, F., et al. (2008). Weekly concomitant boost in adjuvant radiotherapy for patients with early breast cancer: preliminary results on feasibility. Tumori, 94(5), 706-11.

10. Bantema-Joppe, E. J., Van der Laan, H. P., De Bock, G. H., et al. (2011). Three-dimensional conformal hypofractionated simultaneous integrated boost in breast conserving therapy: results on local control and survival. Radiotherapy and oncology, 100(2), 215-20.

11. Van der Laan, H. P., Dolsma, W. V, Maduro, J. H., et al. (2007). Three-dimensional conformal simultaneously integrated boost technique for breast-conserving radiotherapy. International journal of radiation oncology, biology, physics, 68(4), 1018-23.

12. Dale R.G. (1985). The application of the linear quadratic dose-effect equation to fractionated and protracted radiotherapy. Br J Radiol;58:515-528.

13. Owen, J., Ashton, A., Bliss, J., et al. (2006). Effect of radiotherapy fraction size on tumour control in patients with early-stage breast cancer after local tumour excision: long-term results of a randomised trial. Lancet Oncology, 7(6), 467-71.

14. Gray M, James R, Beryl M, et al. (1991). Primary Breast Irradiation in Large- Breasted or Heavy Women: Analysis of Cosmetic Outcome. Int J Radiant Oncol Biol Phys 21, 347-354.

15. Goldhirsch A, Winer EP, Coates AS, et al. (2013). Personalizing the treatment of women with early breast cancer: highlights of the St Gallen International Expert Consensus on the Primary Therapy of Early Breast Cancer 2013. Ann Oncol ;24(9):2206-23.

16. Formenti SC, Gidea-Addeo D, Goldberg JD, et al. (2007). Phase I-II trial of prone accelerated intensity modulated radiation therapy to the breast to optimally spare normal tissue. J Clin Oncol; 25:2236-42.

17. Freedman GM, Anderson PR, Goldstein LJ, et al. (2007). Four-week course of radiation for breast cancer using hypofractionated intensity modulated radiation therapy with an incorporated boost. Int J Radiat Oncol Biol Phys; $68: 347-53$.

18. Guerrero, M., Li, X., Earl, M.,et al. (2004). Simultaneous integrated boost for breast cancer using IMRT: a radiobiological and treatment planning study. International Journal of Radiation Oncology Biology Physics, 59(5), 1513-1522.

19. Hijal, T., Fournier-Bidoz, N., Castro-Pena, P., et al. (2010). Simultaneous integrated boost in breast conserving treatment of breast cancer: a dosimetric comparison of helical tomotherapy and three-dimensional conformal radiotherapy. Radiotherapy and oncology, 94(3), 300-6.

20. Hurkmans, C. W., Meijer, G. J., Van Vliet-Vroegindeweij, C.,et al. (2006). High-dose simultaneously integrated breast boost using intensity-modulated radiotherapy and inverse optimization. International journal of radiation oncology, biology, physics, 66(3), 923-30.

21. Jalali, R., Malde R., Bhutani R, et al. (2008). Prospective evaluation of concomitant tumor bed boost with whole breast irradiation in patients with locally advanced breast cancer undergoing breast-conserving therapy. Breast, 17(1), 64-70.

22. Mayo C, Lo YC, Fitzgerald TJ, Urie M. (2004). Forwardplanned, multiple-segment, tangential fields with concomitant boost in the treatment of breast cancer. Med Dosim; 29:265-70.

23. McDonald MW, Godette KD, Whitaker DJ, et al. (2010). Three-year outcomes of breast intensity-modulated radiation therapy with simultaneous integrated boost. Int J Radiat Oncol Biol Phys; 77:523-30.

24. Morganti AG, Cilla S, Valentini V, et al. (2009). Phase I-II studies on accelerated IMRT in breast carcinoma: technical comparison and acute toxicity in 332 patients. Radiother Oncol; 90:86-92.

25. Nicolini G, Clivio A, Fogliata A, et al. (2009). Simultaneous integrated boost radiotherapy for bilateral breast: a treatment planning and dosimetric comparison for volumetric modulated arc and fixed field intensity modulated therapy. Radiat Oncol; 4:27.

26. Raiyawa $\mathrm{T}$, Lertbutsayanukul C, Rojpornpradit $\mathrm{P}$. (2009). Late effects and cosmetic results of simultaneous integrated boost versus sequential boost after conventional irradiation in breast-conserving therapy; outcome of 7 months follow-up. J Med Assoc Thai; 92:390-7.

27. Rong Y, Fahner T, Welsh JS. (2008). Hypofractionated breast and chest wall irradiation using simultaneous in-field boost IMRT delivered via helical tomotherapy. Technol Cancer Res Treat; 7:433-9.

28. Singla, R., King, S., Albuquerque, K., et al. (2006). Simultaneous-integrated boost intensity-modulated radiation therapy (SIB-IMRT) in the treatment of earlystage left-sided breast carcinoma. Medical Dosimetry, 31(3), 190-6.

29. Howlader N, Noone AM, Krapcho M, et al. (eds). SEER Cancer Statistics Review, 1975-2010, National Cancer Institute. Bethesda, MD. http://seer.cancer.gov/ csr/1975_2008/, based on November 2010 SEER data submission, posted to the SEER web site.

30. Dey S, Soliman AS, Hablas A, et al. (2010) Urbanrural differences in breast cancer incidence by hormone receptor status across 6 years in Egypt. Breast Cancer Res Treat, 120:149-160.

31. Omar S, Khaled H, Gaafar R, et al.(2003). Breast cancer in Egypt: a review of disease presentation and detection strategies. East Mediterr Health J. ;9(3):448-63.

32. Lund MJ, Butler EN, Hair BY, et al. (2010). Age/race differences in HER2 testing and in incidence rates for breast cancer triple subtypes: a population-based study and first report. Cancer, 116:2549-2559. 


Vol. 9| No. 3-4 $2013 \quad$ Salah El-Mesidy et al.

33. Bantema-Joppe, E. J., Schilstra, C., De Bock, G. H., et al. (2012). Simultaneous integrated boost irradiation after breast-conserving surgery: physician-rated toxicity and cosmetic outcome at 30 months' follow-up. International journal of radiation oncology, biology, physics, 83(4), e471-7.

34. Teh, A. Y. M., Walsh, L., Purdie, T. G., et al. (2012). Concomitant intensity modulated boost during whole breast hypofractionated radiotherapy--a feasibility and toxicity study. Radiotherapy and oncology, 102(1), 89-95.

35. El-Mesidy S, El-Kashif A, El- Sherbini N, et al. (2012). uncomplicated tumour control Probability (utcP) in post-operative radiotherapy of left breast cancer- three dimensional conformal versus Intensity Modulated radiation therapy (IMrt). Kasr El-aini J.Clin.Oncol.nucl. med, 8 (1-2):40-48.

36. El-Mesidy S, Mousa M, Atteya H, et al. (2009). Two dimensional versus 3-dimensional radiation therapy in the management of operable left breast cancer. Kasr El-Aini J.Clin.Oncol. Nucl.Med, 5 (3-4):3-9.

37. Van der Laan HP, Dolsma WV, Schilstra C et al. (2010) Limited benefit of inversely optimised intensity modulation in breast conserving radiotherapy with simultaneously integrated boost. Radiother Oncol; 94: 307-12. 